\title{
Psicología, Ética y Seguridad Nacional: El Rol de los Psicólogos
}

\section{Psychology, Ethics and National Security: The Role of Psychologists}

\author{
Elizabeth Lira \\ Universidad Alberto Hurtado
}

\begin{abstract}
Los interrogatorios abusivos y las torturas en Abu Ghraib en Irak y en la Bahía de Guantánamo en Cuba han generado preocupaciones éticas sobre la participación de los psicólogos en los interrogatorios, así como en la investigación y entrenamiento requerido en la lucha contra el terrorismo. Este ensayo describe la evolución y las preocupaciones respecto de este debate en la Asociación Americana de Psicólogos, incluyendo los cambios ocurridos después del referéndum de Septiembre de 2008 y la aprobación de una nueva política que prohíbe que los psicólogos se involucren en interrogatorios en los recintos de detención. El texto incluye algunas referencias a la lucha contra la tortura bajo el régimen militar en Chile (1973-1990) y concluye con algunas reflexiones acerca del rol de los psicólogos, el bien común y los regímenes de seguridad nacional.
\end{abstract}

Palabras clave: psicología, ética, rol profesional, tortura, seguridad nacional.

\begin{abstract}
Abusive interrogation and torture at Abu Ghraib in Iraq and Guantanamo Bay in Cuba have raised ethical concerns about the participation of psychologists in interrogation, research, and training associated with the fight against terrorism. This essay describes the evolution and concerns on this debate within the American Psychological Association, including the changes introduced following the referendum of September 2008 that approved a new policy against any involvement of psychologists in interrogation or any other procedures at detention sites. The text includes some references on the struggle against torture under the military regime in Chile (1973-1990) and concludes with some reflections on the role of psychologists, common good and regimes of national security.
\end{abstract}

Keywords: psychology, ethic, professional role, torture, national security.

\section{Introducción}

Las fotografías de torturas y abusos de prisioneros en la cárcel de Abu Ghraib en Irak recorrieron el mundo en 2004. Mostraban a personal militar torturando a prisioneros iraquíes. El gobierno norteamericano argumentó que los abusos fueron cometidos por iniciativa propia de personal de bajo rango, desconociendo que la tortura estuviera incorporada a las prácticas oficiales. Como resultado de la investigación, los que estaban directamente involucrados fueron juzgados en una corte marcial, siendo sentenciados a prisión, rebajados de rango o expulsados del servicio, según el mérito de cada caso. Las autoridades expresaron que lo sucedido en

\footnotetext{
Elizabeth Lira Kornfeld, Universidad Alberto Hurtado, Santiago, Chile.

La correspondencia relativa a este artículo debe ser dirigida a Elizabeth Lira Kornfeld, Directora del Centro de Ética, Universidad Alberto Hurtado, Cienfuegos 25, Santiago, Chile. E-mail: elira@uahurtado.cl
}

Abu Ghraib los había horrorizado pero que se habían aprendido las lecciones y que las condiciones de los prisioneros habían mejorado considerablemente (Schmitt \& Shanker, 2005, Diciembre 25).

El debate acerca de los interrogatorios de los sospechosos de terrorismo empezó poco después de los ataques del 11 de septiembre de 2001, cuando trascendió que la administración del presidente George W. Bush tenía prisioneros en cárceles secretas y que los detenidos estaban siendo torturados. Desde entonces, la discusión acerca de la legalidad de las prácticas habituales en los interrogatorios de los supuestos terroristas ha sido un tema recurrente en la opinión pública. En 2005, Alberto R. Gonzales, en su calidad de Procurador General de los Estados Unidos, respaldó en un documento secreto el endurecimiento de las técnicas de interrogatorio, combinando métodos de tortura física y psicológica con el fin de superar la barrera del terror de los sospechosos. A su vez, el Departamento de Justicia declaró que los métodos de interrogatorio de la Central Intelligence 
Agency (CIA) se ajustaban a los estándares legales del país (Shane, Johnston \& Risen, 2007, Octubre 4). En varias ocasiones el Congreso y la Corte Suprema de los Estados Unidos han intervenido con el fin de poner límites a las condiciones de los interrogatorios, pero el gobierno ha logrado disponer hasta ahora de un margen legal muy amplio para los métodos más duros, es decir, las torturas. La Corte Suprema de los Estados Unidos estableció en 2006 que las Convenciones de Ginebra eran aplicables a los prisioneros de Al Qaeda. Poco después, el Presidente Bush reconoció la existencia de prisioneros en las cárceles secretas de la CIA y ordenó que fueran enviados a Guantánamo en Cuba. No obstante, los sospechosos encarcelados no han sido considerados oficialmente "presos políticos", sino prisioneros "bajo custodia" de los Estados Unidos.

Las dudas acerca de los límites legales de las prácticas de interrogatorios duros (enhanced) no serían fáciles de disipar. Cuando esa política fue cuestionada por distintos sectores de la opinión pública, las autoridades justificaron su actuar señalando que, gracias a esos procedimientos, se había servido al país al desmantelar los complots terroristas, permitiendo salvar vidas inocentes. Aseguraron que se actuaba estrictamente de acuerdo a la ley de los Estados Unidos. Pero también se dejaba en claro que cualquier método sería aplicable si el detenido resultare sospechoso de disponer de información crucial acerca de atentados terroristas. Las denuncias han sido constantes y fundamentadas, señalando que los prisioneros eran sometidos a torturas con la justificación que sin esas medidas no se produciría la información de inteligencia requerida para prevenir nuevos atentados terroristas (Arrigo \& Long, 2008; Soldz, Olson, Reisner, Arrigo \& Welch, 2008, Julio 22).

La Asociación de Psicólogos de los Estados Unidos (American Psychological Association [APA]) ha sido sacudida por las tensiones que se han derivado de la participación de psicólogos en los interrogatorios duros, en los que se utilizan métodos superiores calificables como torturas. Sin embargo, tal vez el asunto de mayor conflictividad ha sido la información pública sobre la contribución de algunos psicólogos al perfeccionamiento de las técnicas de tortura en el marco político de la lucha contra el terrorismo. Dichas técnicas han integrado la investigación científica realizada por miles de académicos en universidades prestigiadas durante décadas y cuyo financiamiento provino en muchos casos de la CIA (Lemov, 2006).
La discusión acerca de la ética del ejercicio profesional, así como la resistencia moral y política ante la participación de los psicólogos y otros profesionales en prácticas que corroen la dignidad humana, ejercidas en nombre del bien común, no es nueva. En Chile, durante la dictadura militar (1973-1990), el Colegio de Psicólogos y el Colegio Médico se vieron involucrados en problemas análogos en relación con la ética de la práctica profesional y científica en ese período. Durante la década de 1980 los profesionales chilenos recibieron el apoyo y la solidaridad de los gremios profesionales de otros países, entre ellos de asociaciones profesionales y académicas de los Estados Unidos. Esos grupos ejercieron presión sobre distintos organismos de la sociedad chilena y sobre el gobierno, con el fin de impedir que continuaran las violaciones de derechos humanos, en particular, la práctica de la tortura.

La situación surgida en la APA reproduce la discusión sobre las justificaciones políticas (en nombre de la defensa de la patria y de la seguridad interior del Estado) que tendrían algunas prácticas antiéticas en contextos de guerra y de la lucha contra el terrorismo, como las que se produjeron en distintos países de América Latina durante la segunda mitad del siglo XX bajo las dictaduras militares y regímenes de facto. En América Latina, la discusión sobre estos temas desapareció de las esferas académicas y profesionales con las transiciones políticas, como si las violaciones de derechos humanos hubieran sido asuntos completamente superados.

La discusión en los Estados Unidos abre interrogantes sobre el condicionamiento político del ejercicio de la profesión. Estos temas requieren de mayor reflexión, precisamente por su recurrencia en un mundo globalizado en el que, al mismo tiempo que se han alcanzado los más altos niveles de intercambios académicos y profesionales, los mínimos éticos inherentes al desempeño profesional y a la convivencia social y política no están garantizados. En el caso de los Estados Unidos, la resolución de estos dilemas trasciende a los gremios directamente involucrados, incidiendo sobre los mínimos éticos en la lucha internacional contra el terrorismo.

Debate sobre la Ética, el Rol Profesional y la Seguridad Nacional en los Estados Unidos

En 2005, diversos grupos de psicólogos de los Estados Unidos y colegas de diferentes países 
efectuaron una Petición a la Asociación Americana de Psicólogos, denunciando el incumplimiento por parte del gobierno de los Estados Unidos de la Convención de Ginebra y de la Convención de las Naciones Unidas en Contra de la Tortura, en el trato de detenidos bajo su custodia y de la supuesta participación de psicólogos en el maltrato de detenidos. En ella se señalaba, en primer lugar, la gran preocupación de estos profesionales ante:

La posición adoptada por parte de la administración del presidente Bush, la cual excluye la aplicación de la Convención de Ginebra y la Convención de las Naciones Unidas Contra la Tortura a los detenidos en Guantánamo, Abu Ghraib, Afganistán y otros lugares (...) nos preocupan las persistentes declaraciones sobre la supuesta participación de algunos de nuestros colegas psicólogos y de otras áreas de la salud mental en casos de tortura y/o trato cruel, degradante e inhumano de los detenidos, participación que de ser probada, representa una violación directa del código de ética de la Asociación Americana de Psicólogos, American Psychological Association-APA. (The Ignacio Martin Baró Foundation for Mental Health and Human Rights, 2005, ๆ 2-3)

\section{La declaración continuaba señalando:}

Ha existido controversia dentro de la APA sobre cómo clarificar de la mejor manera la dimensión ética referente a la participación de psicólogos en lo que se ha llamado "actividades de seguridad nacional". Un informe del grupo de trabajo presidencial de la APA concluyó que hay un rol para los psicólogos en actividades relacionadas a la seguridad nacional, y que el Código de la APA es "fundamentalmente adecuado para el tratamiento de los dilemas éticos que podrían surgir en el contexto del trabajo relacionado a la seguridad nacional". Sin embargo, en algunas secciones dentro de la APA (como la División sobre Justicia Social) y en organizaciones tales como Psicólogos por la Responsabilidad Social/Psychologists for Social Responsiblity se argumenta que la APA ha demostrado una falta de determinación para tomar en cuenta seriamente el Código de Ética, al no adoptar los estándares internacionales de derechos humanos como marco para la aplicación de dicho Código, así como también el no pedir una investigación sobre las supuestas violaciones éticas por parte de psicólogos. († 4)

La petición instaba finalmente a la APA para que condenara el uso de métodos coercitivos en interrogatorios (privación del sueño, hostigamientos basados en las creencias religiosas, diferencias culturales, orientación sexual o identidad de género de los detenidos) y subrayaba la necesidad de acciones específicas sobre la materia:

Exigimos que la APA establezca una comisión independiente con el objetivo de investigar la supuesta participación directa o indirecta de psicólogos en el abuso y tortura física y psicológica de los detenidos bajo custodia de los Estados Unidos (ya sea como asesores, consultores, especialistas, investigadores, o profesionales proporcionando servicios para el cuidado). Y que se responsabilice a aquellos psicólogos que se encuentren involucrados en dichas prácticas. ( $(9)$

Creemos que los Estados Unidos pueden y deben demostrar, aún en tiempos de crisis, la más elevada conducta moral y ética, convocamos a todas las agencias del gobierno, incluyendo al sector militar y al Departamento de Defensa a establecer políticas que respeten las convicciones éticas de los profesionales y trabajadores de la salud mental, asegurando que no se contraten ni trabajadores de la salud mental ni consultores y asesores de la salud mental independientes, tampoco que se les pida su participación directa o indirecta en prácticas contrarias a la Convención de Ginebra y a la Convención de las Naciones Unidas Contra la Tortura. (\$10)

A su vez, el Programa de Derechos Humanos de la Asociación Americana para el Avance de las Ciencias (AAAS) denunció que había numerosas evidencias acerca de la estrecha coordinación entre la CIA y personal militar de los Estados Unidos para desarrollar y utilizar técnicas abusivas en los interrogatorios de los supuestos terroristas. De acuerdo al documento de la AAAS, había un selecto grupo de psicólogos dedicado a la reingeniería del programa secreto Survival, Evasion, Resistance and Escape (SERE) ${ }^{1}$. Se trataba de revertir y utilizar en

1 Traducción de SERE: Sobrevivencia, Evitación, Resistencia y Escape. 
los interrogatorios las mismas técnicas diseñadas originalmente para entrenar a los soldados con el fin de resistir torturas en caso de ser capturados y sometidos a tratamientos brutales (Chow, 2005).

En ese mismo documento se dejaba constancia que el Comité Internacional de la Cruz Roja había denunciado graves violaciones a la ética médica en los interrogatorios, incluyendo el acceso a las fichas médicas de los detenidos por parte de equipos profesionales (psiquiatras y médicos), con el fin de diseñar planes de interrogatorios individualizados. Amnistía Internacional denunció también la violación del juramento hipocrático y de los principios de la ética profesional en esos contextos. En esas denuncias se insistía que la función de cuidado y atención profesional de los prisioneros no era compatible con la contribución al perfeccionamiento de los tratos abusivos y las formas de tortura a los que eran sometidos dichos prisioneros. No obstante, la posición oficial era otra. El Dr. David Tornberg, Asistente del Secretario de la Defensa para Asuntos de Salud, escribió en el New England Journal of Medicine en 2005 (citado en Chow, 2005) que los profesionales de la salud, fuera de circunstancias excepcionales que amenazaran la vida de su paciente, no estaban obligados a proporcionar ayuda médica a los prisioneros. En consecuencia, los profesionales de salud mental podían ser consultados por los interrogadores sobre todos los aspectos del proceso de interrogatorio y podían aconsejar sobre las técnicas y supervisar el proceso sin violar los códigos de ética.

El grupo de trabajo designado por la directiva de la APA sobre ética profesional y seguridad nacional (APA Presidential Task Force on Psychological Ethics and National Security) entregó un informe en 2005 (APA, 2005) declarando la oposición de la APA a la tortura y su compromiso con el código de ética profesional vigente. Sobre las consultas durante los interrogatorios, estableció que los psicólogos tenían la responsabilidad ética de informar y alertar a las autoridades correspondientes acerca de las prácticas de tortura.

El psicólogo jefe del Equipo de Psicólogos del Comando de Operaciones Especiales del Ejército (Army Special Operations Command's Psychological Directorate), Coronel Morgan Banks, el más antiguo en el programa SERE, contribuyó a redactar el borrador de los lineamientos éticos de la APA en relación con la lucha contra el terrorismo (Benjamin, 2007, Junio 21). En dicho comité se diseñó la política pública sobre la participación de los psicólogos en programas de seguridad nacional y se describió el rol de los psicólogos empleados por la CIA, el Servicio Secreto o el Federal Bureau of Investigation (FBI), estableciendo que el cliente era la agencia de gobierno y, en último término, el pueblo de los Estados Unidos. La acción de los psicólogos debía asegurar la protección de los inocentes (y de la sociedad), contribuyendo a encarcelar, debilitar o incluso matar al perpetrador potencial (Arrigo \& Long, 2008).

Al mismo tiempo, de acuerdo a las recomendaciones del informe, la APA reafirmó la resolución del Consejo de 1986, que apoyaba la declaración de Naciones Unidas (ONU) sobre la Convención contra la Tortura y Otros Tratos Crueles Inhumanos y Degradantes y la declaración de la ONU sobre los Principios de la Ética Médica. Seis de los 10 psicólogos que redactaron ese borrador formaban parte de alguna instancia militar (Benjamin, 2007, Junio 21).

Según fuentes del Congreso de los Estados Unidos y de profesionales de salud mental, dos psicólogos, James Mitchell y Bruce Jessen, fueron investigados por el Comité de Servicios Armados (Armed Services Committee), presidido por el senador demócrata Carl Levin, por el abuso a prisioneros bajo custodia de los Estados Unidos (Benjamin, 2007, Junio 21, Junio 25; Soldz, Reisner \& Olson, 2007, Junio 7). Mitchell y Jessen habían trabajado contratados por la CIA desde el 11 de septiembre de 2001. Estaban incorporados al programa SERE, cuya escuela principal se encuentra en Fort Bragg, y eran responsables de operaciones especiales de interrogatorios simulados a los prisioneros, utilizando métodos como privación sensorial e inmersión bajo el agua hasta la asfixia, conocida como "submarino" (en inglés waterboarding), en el marco de un programa diseñado de manera específica para ello.

El informe desclasificado de la CIA en 2004 daba cuenta que, después del 11 de septiembre de 2001, el grupo de psicólogos ligado a SERE había trabajado para revertir las técnicas diseñadas para entrenar a los soldados en la resistencia a la tortura, reorientándolas como técnicas de interrogatorio. Se afirmaba que durante el entrenamiento los soldados eran sometidos a condiciones extremas: privación del sueño en jornadas prolongadas; exposición de su desnudez y humillación sexual; ejercicios extenuantes; posiciones forzadas y aplicación del "submarino". Se establecía que los psicólogos habían sido decisivos en los entrenamientos para resistir esas técnicas y para transformarlas posteriormente 
en poderosos recursos para interrogar a los supuestos terroristas (American Civil Liberties Union, 2008, Abril 30; Benjamin, 2007, Junio 21).

Estas técnicas habían sido utilizadas con prisioneros sospechosos de pertenecer a Al Qaeda en Guantánamo y también en Irak y Afganistán, a pesar de haber sido negadas sistemáticamente por las autoridades con anterioridad a esa desclasificación. Según las denuncias, Mitchell exigía que se aplicaran técnicas más duras para desajustar a los prisioneros y desmontar sus defensas psicológicas, creando en ellos un sentimiento de desamparo, según las declaraciones que había realizado sobre este tema en 2005 (Benjamin, 2007, Junio 21). Otras denuncias confirmaban las irregularidades de los interrogatorios en Guantánamo y el riesgo que los prisioneros fueran sometidos a torturas (Ackerman, 2007, Junio 22).

Esta información generó diversas reacciones y denuncias que fueron enardeciendo la discusión. En Junio de 2007 un grupo de psicólogos hizo pública una carta dirigida a la presidenta de la APA, Sharon Brehm, identificando a otro psicólogo empleado por la CIA, R. Scott Shumate. Le decían:

Le escribimos como psicólogos preocupados por la participación de nuestra profesión en los interrogatorios abusivos a los detenidos por seguridad nacional en Guantánamo, Irak y Afganistán, y en las cárceles secretas (black sites). Se ha violado la ética de la APA. Nadie puede discutir ahora que los psicólogos y la Psicología han sido directa y oficialmente responsables del desarrollo de técnicas abusivas de interrogatorio que se encuentran en la frontera de la tortura. (Benjamin, 2007, Junio 21, ๆ 6)

Tiempo después, el 1 de Noviembre de 2007, un grupo de psicólogos de organismos de derechos humanos e instituciones académicas dirigieron una carta a los senadores Jay Rockefeller y Christopher Bond. Les hacían presente la preocupación por el rol de los psicólogos en los interrogatorios de prisioneros bajo custodia de los Estados Unidos, afirmando que los psicólogos habían jugado un rol central en los métodos de tortura empleados ilegalmente por los Estados Unidos a través de los agentes de la CIA. Señalaban que, como profesores, clínicos e investigadores, solicitaban al Congreso que prohibiera esos procedimientos abusivos y que se asegurara que los profesionales de la salud, incluyendo a los psicólogos, no estuvieran implicados en funciones que los llevara a violar sus obligaciones éticas como profesionales de la salud (Soldz, 2007, Noviembre 2). Afirmaban que las técnicas de tortura utilizadas se habían basado en el viejo paradigma inventado hacía más de 55 años por la CIA, Debility, Dread and Dependency, con el fin de debilitar a los prisioneros, infundir miedo y crear relaciones de dependencia, como fuera denunciado en el informe Leave No Marks (No Dejar Huellas) de Physicians for Human Rights (Médicos por los Derechos Humanos) y $\mathrm{Hu}$ man Rights First (Los Derechos Humanos Primero), concluyendo que dichas "técnicas causan daño mental y físico severo y prolongado a los detenidos y someten a los que los aplican a un riesgo serio de convertirse en criminales" (Soldz, \ 10).

El texto enfatizaba la gran preocupación de los firmantes por estos asuntos y mencionaba la importancia que había tenido la clara definición de la Asociación Médica Americana (American Medical Association), de la Asociación Americana de Enfermeras (American Nurses Association) y de la Asociación Americana de Psiquiatras (American Psychiatric Association) en contra de la participación de sus miembros en torturas, enfatizando que el fundamento de las profesiones de la salud ha sido el imperativo ético de no causar daño (Soldz, 2007, Noviembre 2). Subrayaba que la APA era la única asociación profesional que no había declarado inequívocamente que prohibía a sus miembros participar en interrogatorios potencialmente abusivos. El documento finalizaba con un conjunto de recomendaciones en función de corregir la falta de pronunciamiento de la APA sobre los temas en discusión (Soldz).

La asociación Psicólogos por la Responsabilidad Social difundió un manifiesto para detener la tortura y el abuso de los prisioneros extranjeros, señalando que se oponía radicalmente a las detenciones ilegales, al maltrato y al abuso de los prisioneros que habían sido detenidos por diversas instancias militares de los Estados Unidos, la CIA y otras agencias. Llamaba a los ciudadanos a garantizar el debido proceso a los detenidos e instaba a la APA a impedir que los psicólogos participaran en torturas. Solicitaba el cierre de Guantánamo y de los lugares secretos de detención y exigía que los prisioneros fueran trasladados a recintos donde se garantizara de manera transparente los estándares internacionales de derechos humanos (Psychologists for Social Responsibility, 2007).

En los primeros días de Febrero de 2008 Kenneth S. Pope, presidente del Comité de Ética, en una carta 
dirigida al presidente de la APA, Alan Kazdin, renunció a la organización. Fundaba su decisión en su desacuerdo con las definiciones éticas de la APA en los seis años precedentes, las que, a su juicio, habían alejado a la asociación de sus fundamentos éticos, de sus tradiciones históricas y de sus valores básicos, lo que le impedía continuar con su membresía (Pope, 2008). Pocos días antes, Jeffrey Kaye había presentado su renuncia a la APA, fundando esta decisión en hechos que, a su juicio, evidenciaban la cooperación de la APA en prácticas del gobierno que violaban la ley, el respeto de los derechos humanos y el código de ética de la APA (Kaye, 2008, Marzo 6).

El 22 de Febrero de 2008 la APA hizo pública la enmienda a la reafirmación de su posición contra la tortura y otros tratos crueles, inhumanos y degradantes o castigos y su aplicación contra individuos definidos en el Código de los Estados Unidos como "combatientes enemigos" (Amendment to the Reaffirmation of the American Psychological Association Position Against Torture and Other Cruel, Inhuman, or Degrading Treatment or Punishment and its Application to Individuals Defined in the United States Code as "Enemy Combatants", APA, 2008, Febrero 22). El texto indicaba que se había resuelto una condena inequívoca a todas las técnicas consideradas como torturas o tratos crueles inhumanos y degradantes bajo la Convención contra la Tortura de la ONU, las Convenciones de Ginebra, los principios de la ética médica sobre el rol del personal de salud en el trato de prisioneros y la declaración de Tokio de la Asociación Médica Mundial. Se establecía una prohibición absoluta sobre determinadas técnicas, entre las cuales se mencionaban las falsas ejecuciones, la humillación sexual, religiosa y cultural, la explotación de los miedos y fobias o de la psicopatología de los individuos, el aislamiento y la privación del sueño a un individuo o a miembros de una familia. Finalizaba señalando que se prohibía a los psicólogos planificar, diseñar, participar o contribuir al uso de estas técnicas (APA). Pero esta definición no anulaba las definiciones anteriores que justificaban la participación profesional y científica si ella era requerida en nombre del bien común, en el marco de la lucha contra el terrorismo. Por eso, durante 2008, diversos comités de psicólogos intensificaron las presiones para que estas definiciones fueran transformadas en una política oficial de la APA.

\author{
La Tortura: Discusión sobre el Rol de los \\ Psicólogos
}

La discusión sobre los dilemas éticos en la actuación profesional de los psicólogos en los Estados Unidos -y en otros países- en relación con la tortura de sospechosos de terrorismo se ha mantenido candente.

El presidente del Comité de Ética de la APA, Stephen Behnke, afirmó que la participación de los psicólogos en los interrogatorios mejoraba las condiciones de los detenidos, al contribuir a mantener dichos interrogatorios en un marco ético, legal, protegido y efectivo, separando ese rol del correspondiente al cuidado de la salud del prisionero. Afirmó que los psicólogos, al sospechar algún abuso, recomendaban la interrupción del proceso para que el personal médico evaluara al detenido. De este modo, según dijo, el compromiso de la APA ha permitido detener los interrogatorios que sobrepasan los límites éticos apropiados (Soldz, 2008, Mayo 27).

En la década de 1980, se incorporaron médicos a los interrogatorios que hacía la Central Nacional de Informaciones (CNI), la policía política secreta en Chile. Se afirmó entonces, como ahora en Estados Unidos, que era una forma de proteger al prisionero. El Colegio Médico de Chile denunció la actuación de los médicos en los interrogatorios y en cualquier otra actuación relacionada con la situación de los prisioneros políticos como una conducta contraria a la ética profesional. Se hizo referencia a las circunstancias en las que los médicos "han examinado a víctimas de la tortura antes de su liberación, pero no informaron sobre la existencia de lesiones derivadas de la tortura", señalando que ese examen final era una rutina que en lugar de proteger al prisionero "permite todo tipo de excesos en total impunidad", al contar con la complicidad de los médicos para desvirtuar las denuncias de las propias víctimas (Stover, 1987, pp. 73-74). Sobre este punto, al analizar el rol de los médicos en la represión política en el Cono Sur en América Latina, Stover señalaría que "la supervisión de la tortura desde una perspectiva médica equivale a la evaluación periódica de la capacidad de la víctima para soportar un tratamiento cruel" (p. 69).

Stephen Soldz, director del Research, Evaluation, and Program Development del Boston 
Graduate School of Psychoanalysis (Investigación, Evaluación y Programa de Desarrollo de la Escuela de Graduados de Psicoanálisis), denunció que uno de los ex presidentes de la APA, Martin Seligman, contribuyó al desarrollo de las técnicas de tortura y apoyó a los psicólogos que eran consultores de la CIA, James Mitchell y Bruce Jessen. Seligman negó tales afirmaciones, reconociendo únicamente haber dictado algunas conferencias en la base naval de San Diego en 2002, y señalando que estaba en contra de la tortura (Soldz, 2008, Julio 14). Los psicólogos, empleados por el Departamento de Defensa para la reingeniería del programa SERE, ya no eran miembros de la APA.

Soldz (2008, Julio 13) menciona que en el libro de Jane Mayer, The dark side, sobre la participación de psicólogos en las torturas y malos tratos a los detenidos durante la administración Bush, se informaba que Mitchell hizo uso del modelo de desesperanza aprendida (modelo conocido en ese contexto como indefensión aprendida) en el diseño de los interrogatorios. Varios ejemplos confirman lo aseverado. En la denuncia de Mayer se cita, entre otros, que:

Un prisionero fue encerrado en posición fetal en una jaula demasiado estrecha para él sin poder hacer otra cosa que yacer en una posición fetal. La jaula había sido diseñada no solo para impedir el movimiento sino para dificultar la respiración. Cuando el detenido estaba fuera de la jaula esta permanecía siempre ante su vista; el mecanismo de tortura radicaba en mantener alerta al prisionero arriesgando volver a estar encerrado en la jaula. (...) la mayoría de los detenidos fueron sometidos a largos períodos de aislamiento, a menudo en total oscuridad, permaneciendo desnudos. El contacto humano era mínimo. En un caso, el único contacto humano con el detenido se producía con la única visita diaria de un enmascarado que aparecía para declarar: 'Tú sabes lo que quiero' para luego desaparecer. (Soldz et al., 2008, Julio 22, 9 8-10)

El 25 de Junio de 2008 el presidente de la Asociación Noruega de Psicólogos, Tor Levin Hofgaard, representante a su vez del Comité Nórdico de Asociaciones de Psicólogos, dirigió una carta a sus colegas de la APA, expresando la preocupación de los miembros de las asociaciones nórdicas que representaba, más aún después de la desclasificación de los informes militares en 2006 (Office of the Inspector General of the Department of Defense, 2006). En su comunicación, Tor Levin Hofgaard reconocía y valoraba los esfuerzos expresados principalmente en la enmienda de 2008 de la APA, pero señalaba la contradicción que aún subsistía: ¿Pueden involucrarse los psicólogos en interrogatorios militares con el fin de evaluar las debilidades del prisionero y recomendar en qué momento se ha de incrementar la presión para obtener información? ¿Puede considerarse que tales conductas son consistentes con los principios de la ética profesional? Estas preguntas, señalaba, pueden inquietar a quienes prefieren pensar que los psicólogos "protegen" a los detenidos de ser torturados y no que "asesoran" a los torturadores en los interrogatorios.

Tor Levin Hofgaard afirmó que la mera presencia de los psicólogos en condiciones y ambientes donde los prisioneros carecen de los derechos más elementales puede ser interpretada como una manera de dar apoyo y legitimidad a la violación de la ley internacional y de los derechos humanos, y preguntaba si la APA tenía algún juicio al respecto. En la carta se analizaba la incompatibilidad entre el código de ética de la APA y su resolución de 2007, que declaraba que, de haber conflicto entre la ley y el código de ética, prevalecería la ley. ¿Cómo se entiende esta resolución cuando los psicólogos trabajan en ambientes en los que se viola sistemáticamente la ley internacional y los derechos humanos como resultado de una política institucional, como ocurre en Guantánamo y en las cárceles secretas de la CIA? Estas preguntan apuntaban a casi los mismos dilemas éticos que interpelaron a los profesionales de la salud y en particular a médicos y psicólogos durante el régimen militar en Chile.

Esas y otras preguntas han hecho emerger, también, la preocupación por la multifacética contribución de algunas investigaciones científicas al perfeccionamiento de las técnicas de tortura y la colaboración de académicos e investigadores de renombre en dichos estudios, es decir, una contribución acumulativa durante décadas, descuidando el registro ético necesario durante su realización y posteriormente durante su aplicación (Lemov, 2005, Noviembre 16).

Como parte de la discusión en desarrollo en la APA, en algunas de sus divisiones se decidió realizar un referéndum el 7 de Septiembre de 2008 sobre una petición resolutiva que establecía que: 
Los psicólogos no pueden trabajar en lugares donde hay personas que están detenidas al margen o en abierta violación de la ley internacional (La Convención de Naciones Unidas contra la Tortura o las Convenciones de Ginebra) o de la Constitución de los Estados Unidos si corresponde, a menos que estén trabajando directamente a favor de las personas que se encuentran detenidas o para una tercera parte independiente que trabaje por los derechos humanos. (APA, 2008, Septiembre 17, ๆ 1)

Esta resolución fue aprobada por 8.792 votos a favor y 6.157 en contra. Será política oficial si es aprobada por la mayoría de los miembros de la APA en la próxima reunión anual de Agosto de 2009.

Con fecha 2 de Octubre de 2008, el presidente de la APA, Alan E, Kazdin, dirigió una carta al presidente George W. Bush, informándole del cambio en la política de la APA. Especificó los criterios acordados sobre el rol profesional de los psicólogos en contextos en los que los derechos de los detenidos han sido violados como ha ocurrido en la Bahía de Guantánamo en Cuba y en las cárceles secretas alrededor del mundo. El presidente de la APA señaló que la nueva política implicaba para los psicólogos la prohibición absoluta de participar en interrogatorios y torturas. Terminó su carta llamándolo a garantizar el bienestar físico y psicológico de quienes se encontraban detenidos, respetar sus derechos señalados en la Convención contra la Tortura y los convenios de Ginebra y asegurarles un debido proceso.

La resolución votada y la carta al Presidente Bush constituyeron importantes avances en el esfuerzo por hacer prevalecer los principios éticos de la profesión. No solo profundizan la resolución de 2007 de la APA, sino que precisan los criterios para resolver los conflictos con las decisiones políticas de las autoridades de gobierno, la ley y el código de ética.

\section{Responsabilidad Social y Respeto a los Derechos Humanos en Chile}

El informe de la Comisión Nacional de Verdad y Reconciliación (1991) hizo una exposición detallada de las violaciones de derechos humanos cometidas durante el régimen militar en Chile (1973-1990). Las prácticas de tortura fueron registradas como una de las causas de muerte de numerosas víctimas. En
2003 el gobierno creó la Comisión Nacional sobre Prisión Política y Tortura (CNPPT) para identificar a las víctimas e implementar una política de reparación para los ex presos políticos y torturados. Cerca de 28 mil ex presos fueron reconocidos (Comisión Nacional sobre Prisión Política y Tortura, 2005) y pudieron acceder a medidas de reparación en los ámbitos de salud y educación y a pensiones. Las cifras estimadas de ex presos, sin embargo, superaban los 50 mil.

El registro de estas situaciones remite a las condiciones políticas del régimen militar y sus efectos. Es preciso recordar que se dictaron nuevas disposiciones legales sobre las asociaciones gremiales en 1979 y que, entre otras medidas, se eliminó la afiliación obligatoria de los profesionales a sus gremios y se redujeron las atribuciones de los colegios profesionales sobre la tuición ética del ejercicio profesional. No obstante, los colegios mantuvieron la representación y la preocupación y vigilancia sobre el ejercicio profesional de sus afiliados. El Colegio Médico de Chile, ante la denuncia de que algunos médicos habrían participado en torturas, después de una investigación interna de la Comisión de Ética, expulsó a ocho médicos al comprobarse dicha participación (Rivas, 1990; Stover, 1987). El Colegio de Psicólogos recibió denuncias sobre psicólogos involucrados en actividades vinculadas a los organismos represivos, pero la información recibida era indirecta e insuficiente y se refería a profesionales que no pertenecían al Colegio en esa época ${ }^{2}$.

Reaccionando ante lo que sucedía en Chile, científicos y académicos de diferentes países reivindicaron en nombre de la ética el respeto por los derechos humanos como principio rector de la convivencia humana y de la investigación con seres humanos y organizaron formas de solidaridad para enfatizar la responsabilidad social de los científicos en relación a la situación que afectaba a sus colegas en otras latitudes. Según la AAAS, la ética era una dimensión principalmente social y el desarrollo de las ciencias y de la investigación, en particular de las ciencias sociales, requería de las libertades públicas y del respeto por los derechos humanos como con-

\footnotetext{
2 Fui miembro de la directiva del Colegio de Psicólogos entre 1984 y 1986. En ese período se recibió la denuncia del agente del Comando Conjunto, Andrés Valenzuela, quien en su declaración describió a algunos psicólogos que trabajaban en la CNI y antes en la Dirección Nacional de Inteligencia (DINA), pero no los identificaba expresamente. El Colegio no pudo iniciar ninguna acción legal, aunque la descripción no dejaba muchas dudas acerca de sus identidades.
} 
diciones fundamentales para su desarrollo (Stover, 1982). Consistente con esa perspectiva, el Comité de Responsabilidad Social y Libertad Científica de la AAAS coordinó sucesivas visitas de científicos a Chile, incluyendo entre ellos a varios Premios Nóbel, quienes manifestaron a las autoridades del país su preocupación por la situación de los académicos perseguidos y encarcelados, rechazando la tortura y las violaciones de derechos humanos como práctica sistemática y la falta de libertad académica.

En 1985, representantes de la Asociación Americana de Psiquiatras (American Psychiatric Association), de la APA y de la Asociación de Médicos y Cirujanos de los Estados Unidos (Physicians and Surgeons Association) visitaron Chile con el fin de conocer las condiciones del ejercicio profesional y libertad académica de sus pares, así como las situaciones de violaciones de derechos humanos que habían afectado a algunos académicos y profesionales. Los representantes del Comité de Relaciones Internacionales en Psicología (Committee on International Relations in Psychology) de la APA, Lillian Comas-Díaz y Amado M. Padilla (1987), entregaron su informe Effects of fear and repression in Chile. Report on Human Rights Fact Finding Mission (Miedo y represión en Chile. Informe de la Misión de Investigación en Terreno) en la $94^{\mathrm{a}}$ Reunión Anual de la APA, realizada en Washington en Agosto de 1986 (APA, 1986). En ese informe se dejaba constancia de las condiciones de riesgo de la actividad de profesionales y académicos que se oponían al régimen militar y, particularmente, de la falta de libertad académica en las universidades, lo que afectaba a la docencia, la investigación y las condiciones de desempeño profesional de sus pares. Dieron cuenta de los informes recibidos de psicólogos clínicos acerca del impacto del contexto político sobre los niños cuyos padres habían sido afectados por la represión política ${ }^{3}$. No era posible pensar en ese entonces que los psicólogos que visitaron Chile, procurando el respeto de los derechos humanos básicos de sus colegas y de todos los chilenos, estarían enfrentados posteriormente a dilemas análogos y que lo que entonces ocurría muy lejos de los Estados

\footnotetext{
3 Fui invitada a formar parte del panel organizado por la APA en la $94^{\circ}$ Reunión Anual para dar cuenta de su misión en Chile. Participó también en el panel el psicólogo chileno Héctor Betancourt, quien se encontraba en ese tiempo en Loma Linda University. El informe entregado en el panel no fue publicado. Los psicólogos que participaron en la misión escribieron un artículo sobre los puntos centrales de su informe (ver ComasDíaz \& Padilla, 1987).
}

Unidos empezaría a ocurrir dentro de sus fronteras y en el ámbito de su responsabilidad profesional y académica.

\section{En Nombre del Bien Común: Reflexiones Finales}

Desde Aristóteles hasta los regímenes de seguridad nacional durante el siglo XX se ha considerado posible suspender, postergar o anular los derechos de los individuos en nombre del bien común. Así ha sido legislado por siglos hasta nuestros días en los estados de excepción constitucional. Ante amenazas diversas de orden ideológico y político, se ha legitimado coyunturalmente el uso de la tortura e incluso el exterminio de otros bajo determinadas circunstancias, contraviniendo las disposiciones del derecho internacional de los derechos humanos y muchas veces también de las constituciones políticas y las leyes vigentes. La legitimidad (y aceptación) de tales prácticas se funda en la deshumanización del otro calificado como "enemigo". Los atributos de peligrosidad de ese enemigo justifican su aniquilación. Los conflictos políticos recientes redefinen y actualizan creencias y prácticas culturales que han justificado las exclusiones y la aniquilación de los otros y que se generalizaron durante todo el siglo XX como justificación de las guerras, los campos de exterminio y las distintas formas de represión política.

La resistencia moral y política ante esos procesos ha tenido distintas expresiones a lo largo de la historia, aunque sus efectos inmediatos fueran limitados. Un ejemplo de ello fue el debate que se llevó a cabo en la Junta de Valladolid (1550-1551) sobre los derechos de los naturales de América y su condición de personas. La discusión tuvo lugar en el Aula Triste del Palacio de Santa Cruz, antiguo Colegio Universitario y hoy sede del Rectorado de la Universidad de Valladolid. Fray Bartolomé de Las Casas (1552) estaba en contra de la conquista de los indígenas, afirmando que no eran esclavos por naturaleza y que poseían legítimamente sus tierras y dominios. Estaba en disputa si los naturales eran racionales. De no demostrarse tal racionalidad, carecerían de derechos y podrían ser esclavizados y aniquilados. Fray Bartolomé de Las Casas, contrariando las creencias predominantes, abogaba por su reconocimiento como personas perfectamente racionales y logró ganar la disputa filosófica (y política) de la época, impidiendo que fueran declarados 
irracionales y, por tanto, no humanos (Beauchot, 1994). Las consecuencias políticas de tal declaración producirían diferencias a favor de los naturales en Ibero América.

Como se ha analizado en este ensayo, distintos grupos profesionales en Estados Unidos se han resistido a que la guerra contra el terrorismo destruya los valores y principios que han sustentado su quehacer académico y profesional. Han advertido en los últimos años que los principios universales sobre el respeto y dignidad de las personas y los estrictos cánones de la ética profesional han sido transgredidos durante el siglo XX por profesionales e investigadores, en distintos momentos y lugares, antes y después de la Declaración Universal de Derechos Humanos de 1948, al contribuir a perfeccionar métodos de control sobre los seres humanos mediante el sufrimiento. Se ha establecido que en distintas universidades e instituciones públicas en varios países se llevaron a cabo estudios destinados a mejorar la eficiencia de modalidades sofisticadas de interrogatorio y tortura durante la guerra fría (Lemov, 2006). Igual cosa ocurrió con los estudios sobre métodos para exacerbar las ansiedades, miedos y deseos en las personas y grupos (Watson, 1982). Los resultados de dichos estudios fueron incorporados a operaciones de guerra psicológica, combinando refinados estudios clínicos con los métodos de otras especialidades de la psicología (Omang, 1985).

Al conocerse las torturas y prácticas aberrantes ejercidas contra prisioneros en Irak en 2004 y la reingeniería del programa SERE, ha salido a la luz pública la contribución de los psicólogos en esas investigaciones y la gran cantidad de recursos científicos y profesionales puestos a disposición de estas políticas, cuyos orígenes pueden rastrearse en las prácticas institucionales de la Inquisición. Es preciso recordar que el tribunal del Santo Oficio ha sido considerado como la primera instancia científica que acumuló experiencia y sistematizó, hace más de 600 años, el saber sobre la tortura (Eymeric, 1376/2006; McCoy, 2006). Los resultados científicos utilizados en el presente en el manejo del terror y la coerción han sido producidos y acumulados durante siglos en una larga cadena de conocimientos y han sido actualizados en base a los recursos tecnológicos disponibles en laboratorios universitarios e instituciones del Estado en distintos lugares del planeta (Lemov, 2005, Noviembre 16; McCoy).

La controversia desarrollada en la APA ha puesto en el centro de la discusión el compromiso de los psicólogos con los principios y estándares éticos de la profesión, cuyo objetivo es el bienestar y la protección de los individuos y grupos con los que se trabaja (APA, 2003, Junio 1). Es contrario a esos principios poner los conocimientos científicos y profesionales al servicio de la tortura de personas catalogadas como enemigos políticos, aunque las autoridades de un gobierno definan que esos procedimientos son indispensables en nombre del bien común. El proceso de discusión deja en claro que la ley debe garantizar el debido proceso y el reconocimiento de los derechos humanos básicos a todas las personas, aun a los individuos sospechosos de atentar contra el bien común en razón de sus ideologías y creencias, y que debe garantizar que nadie será sometido a tratos crueles, inhumanos y degradantes en ninguna circunstancia. Esto forma parte de las legislaciones de los países que suscribieron la Convención contra la Tortura desde 1984, que son la mayoría. Pero, por otra parte, en casi todos los países, los estados de excepción constitucional, las leyes de seguridad interior del Estado y las leyes antiterroristas suelen ser el pretexto para permitir que, bajo circunstancias excepcionales, no solo se suspendan las garantías y derechos individuales, sino que ellos sean atropellados en nombre del bien común. En esas circunstancias excepcionales el discernimiento ético de los científicos y profesionales y, en este caso, de los psicólogos, juega un rol decisivo precisamente en nombre del bien común, asegurando que sus conocimientos estén al servicio de mejorar las condiciones de los individuos, las organizaciones y la sociedad que han sido afectados por el conflicto, manteniendo la autonomía necesaria respecto de los intereses políticos definidos en esas circunstancias como bien común.

La resistencia desplegada por grupos de psicólogos en Estados Unidos ante el riesgo de anulación y subordinación de la ética profesional a intereses políticos coyunturales no ha terminado, aunque se haya resuelto parcialmente en el referéndum recién aprobado. Sin embargo, cualquiera sea su desenlace, esta discusión ofrece oportunidades de reflexión y aprendizaje acerca de los criterios de discernimiento ético sobre el quehacer científico y profesional bajo condiciones políticas críticas en el actual orden mundial. El liderazgo de los Estados Unidos a nivel político y científico tiene una enorme incidencia sobre las prácticas profesionales y científicas de casi todo el orbe y es por eso que esta discusión, aunque por ahora parezca ajena a las preocupaciones inmediatas de los psicólogos chilenos o latinoamericanos, tiene 
una importancia estratégica tanto sobre el perfil de la profesión como sobre los mínimos éticos en cada sociedad. Esos mínimos éticos son indisociables del quehacer académico y profesional y constituyen el fundamento de las condiciones de paz en el ámbito mundial.

\section{Referencias}

Ackerman, S. (2007, Junio 22). GTMO hearings severely flawed, army intelligence officer says. TPM, Muckraker. Extraído el 31 Agosto, 2008, de http://tpmmuckraker.talkingpointsmemo. com/archives/003512.php\#more

American Civil Liberties Union (2008, Abril 30). Newly unredacted report confirms psychologists supported illegal interrogations in Iraq and Afghanistan. New York: Autor, Safe and Free. Extraído el 31 Mayo, 2008, de http://www.aclu.org/ safefree/torture/35111 prs20080430.html

American Psychological Association (1986). Program 94 th Annual Convention, August 22-26. Washington, DC: Autor.

American Psychological Association (2003, Junio 1). Ethical principles of psychologists and code of conduct. APA Online, Ethics. Extraído el 20 Octubre, 2008, de http://www.apa.org/ ethics/code2002.html

American Psychological Association (2005). Report of the APA Presidential Task Force on Psychological Ethics and National Security. Washington, DC: Autor. Extraído el 8 Octubre, 2008, de http://www.apa.org/releases/PENSTaskForceReportFinal. pdf

American Psychological Association (2008, Febrero 22). Amendment to the reaffirmation of the American Psychological Association position against torture and other cruel, inhuman, or degrading treatment or punishment and its application to individuals defined in the United States code as "enemy combatants". APA Online, Governance. Extraído el 31 Mayo, 2008, de http://www.apa.org/governance/resolutions/ amend022208.html

American Psychological Association (2008, Septiembre 17). APA members approve petition resolution on detainee settings. APA Online, Releases. Extraído el 9 Octubre, 2008, de http://www. apa.org/releases/petition0908.html

Arrigo, J. M. \& Long, J. (2008). A lesson for world psychology: Denunciation and accommodation of abusive interrogations by the American Psychological Association. En International Rehabilitation Council for Torture Victims, Preventing Torture within the Fight Against Terrorism Newsletter, 2(5), 2-7. Extraído el 8 Octubre, 2008, de http://www.psysr.org/materials/ Arrigo_Long_IRCT.pdf

Beauchot, M. (1994). Los fundamentos de los derechos humanos en Bartolomé de Las Casas. Barcelona: Anthropos.

Benjamin, M. (2007, Junio 21). The CIA's torture teachers. Psychologists helped the CIA exploit a secret military program to develop brutal interrogation tactics-likely with the approval of the Bush White House. Salon.com, Opinion. Extraído el 2 Febrero, 2008, de http://www.salon.com/news/ feature/2007/06/21/cia_sere/print.html

Benjamin, M. (2007, Junio 25). The CIA's torture teachers: Psychologists helped the CIA exploit a secret military program to develop brutal interrogation tactics. Democracy Now, Past Shows, entrevista de Amy Goodman a Mark Benjamin. Extraído el 31 Mayo, 2008, de http://www.democracynow.org/2007/6/25/ the_cias_torture_teachers_psychologists_helped

Comas-Díaz, L. \& Padilla, A. M. (1987). Miedo y represión política en Chile. Revista Latinoamericana de Psicología, 19, 135-146.

Comisión Nacional sobre Prisión Política y Tortura (2005). Informe de la Comisión Nacional sobre Prisión Política y Tortura. Santiago, Chile: Ministerio del Interior. Extraído el 10 Abril, 2008, de http://www.comisiontortura.cl

Comisión Nacional de Verdad y Reconciliación (1991). Informe de la Comisión Nacional de Verdady Reconciliación (Informe Rettig). Santiago, Chile: Ministerio del Interior. Extraído el 10 Abril, 2008, de http://www.ddhh.gov.cl/ddhh_rettig.html

Chow, L. (2005). Psychology and human rights: The Ignacio Martin-Baro Fund in review. Report on Science and Human Rights, 25(2). Extraído el 10 Abril, 2008, de http://shr.aaas. org/report/xxv/baro.htm

De las Casas, B. (1552). Aquí se contiene una disputa, o controversia: entre el Obispo don fray Bartholomé de las Casas [...] y el doctor Ginés de Sepúlveda. Sevilla: Casa de Sebastián Trujillo. En Colección Biblioteca Nacional, Sala Medina (DIBAM, MC0018798). Versión electrónica extraída el 8 Octubre, 2008, de http://digital.library.wisc.edu/1711.dl/ IbrAmerTxt.Spa0035

Eymeric, F. N. (1376/2006). Manual de inquisidores (Directorivm Inquisitorvm). Madrid: La Esfera de los Libros.

Kaye, J. S. (2008, Marzo 6). Why torture made me leave the APA. AlterNet, Rights and Liberties. Extraído el 31 Agosto, 2008, de http://www.alternet.org/rights/78909

Lemov, R. (2005, Noviembre 16). The birth of soft torture. CIA interrogation technique - a history. Slate, Science. Extraído 31 Julio, 2008, de http://www.slate.com/id/2130301/\#by

Lemov, R. (2006). World as laboratory: Experiments with mice, mazes, and men. New York: Hill and Wang.

McCoy, A. W. (2006). A question of torture. CIA interrogation from the cod war to the war on terror. New York: Henry Holt \& Co.

Office of the Inspector General of the Department of Defense (2006). Review of DoD directed investigation of detainee abuse (U). Washington, DC: Autor. Extraído el 28 Mayo, 2008, de http://www.fas.org/irp/agency/dod/abuse.pdf

Omang J. (1985). The CIA's Nicaragua manual. Psychological operations in guerrilla warfare. New York: Random House.

Pope, K. S. (2008). Why I resigned from the American Psychological Association. Kspope.com, Articles, Research, and Resources in Psychology, Detainee Interrogations. Extraído el 15 Mayo, 2008, de http://kspope.com/apa/index.php

Psychologists for Social Responsibility (2007). Appeal for international support from U.S. psychologists: Condemn psychologist participation in Bush regime detainee abuse. Washington, DC: Autor, End Torture Action Committee. Extraído el 8 Octubre, 2008, de http://www.psysr.org/about/committees/ endtorture/AppealForInternationalSupport.pdf

Rivas, F. (1990). Traición a Hipócrates. Médicos en el aparato represivo de la dictadura. Santiago, Chile: CESOC Editores.

Schmitt, E. \& Shanker, T. (2005, Diciembre 25). U.S., citing abuse in Iraqi prisons, holds detainees. The New York Times, International. Extraído el 2 Febrero, 2008, de http://www. nytimes.com/2005/12/25/international/middleeast/25detain. html?pagewanted $=1 \&$ r $=1$

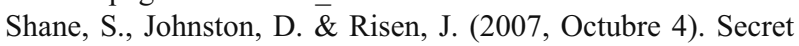 U.S. endorsement of severe interrogations. The New York Times, Washington. Extraído el 15 Mayo, 2008, de http:// www.nytimes.com/2007/10/04/washington/04interrogate. 
html? pagewanted $=1 \&$ r $=1 \&$ adxnnlx $=1209654751$ myiObmHDQlsfaDarY/2IĀQ

Soldz, S. (2007, Noviembre 2). Psychologists against torture. Dissident Voice, Archives. Extraído el 31 Agosto, 2008, de http://www.dissidentvoice.org/2007/11/pyschologists-againsttorture

Soldz, S. (2008, Mayo 27). A critique of Stephen Behnke's letter to the ACLU. American Psychological Association supports psychologist engagement in Bush regime interrogations. CounterPunch, Today's Stories. Extraído el 30 Mayo, 2008, de http://counterpunch.org/soldz05272008.html

Soldz, S. (2008, Julio 13). Martin Seligman second former APA President connected to CIA torturers. Psychoanalysts for Peace and Justice, Psyche, Science, and Society Blog of Stephen Soldz: Psychoanalyst, Psychologist, Researcher, and Activist. Extraído el 31 Julio, 2008, de http://psychoanalystsopposewar. org/blog/2008/07/13/martin-seligman-second-former-apapresident-connected-to-cia-torturers

Soldz, S. (2008, Julio 14). Former APA President Martin Seligman denies involvement in developing CIA tactics. Psychoanalysts for Peace and Justice, Psyche, Science, and Society Blog of Stephen Soldz: Psychoanalyst, Psychologist, Researcher, and Activist. Extraído el 14 Julio, 2008, de http:// psychoanalystsopposewar.org/blog/2008/07/14/former-apapresident-martin-seligman-denies-involvement-in-developingcia-tactics

Soldz, S., Olson, B., Reisner, S., Arrigo, J. M. \& Welch, B. (2008, Julio 22). Torture and the strategic helplessness of the American Psychological Association. Torture after dark. CounterPunch, Today's Stories. Extraído el 28 Julio, 2008, de http://www.counterpunch.org/soldz07232008.html

Soldz, S., Reisner, S. \& Olson, B. (2007, Junio 7). The Pentagon's IG Report contradicts what the APA has said about the involvement of psychologists in abusive interrogations. A Q\&A on psychologists and torture. CounterPunch, Today's Stories. Extraído el 2 Febrero, 2008, de http://www.counterpunch.org/ soldz06072007.html

Stover, E. (1982). Derechos humanos, libertad y responsabilidad científica: problemas y oportunidades en las Américas. En E. Stover \& K. McClesky (Eds.), Informe del Seminario de la AAAS. Los derechos humanos y la cooperación cientifica. Problemas y oportunidades en las Américas (pp. 2-4). Washington, DC: American Association for the Advancement of Science.

Stover, E. (1987). The open secret: Torture and the medical profession in Chile. Washington, DC: American Association for the Advancement of Science, Committee on Scientific Freedom and Responsibility.

The Ignacio Martin Baró Foundation for Mental Health and Human Rights (2005). Petición a la Asociación Americana de Psicólogos. New York: Autor. Extraído el 1 Febrero, 2007, de http://www.martinbarofund.org/contact/petition-APAespanol.htm

Watson, P. (1982). Guerra, persona y destrucción. México, D.F.: Nueva Imagen.

Fecha de recepción: Agosto de 2008.

Fecha de aceptación: Octubre de 2008. 